This Policy Brief was written based on the research findings of the ESRC SDA Initiative Phase I project "Flexible aging: new ways to measure the diverse experience of population aging in Scotland" (ES.K004611.1). It was initially published on project page of the ESRC website:

http://www.esrc.ac.uk/my-esrc/grants/ES.K004611.1/read

However, the ESRC website has since then been moved to ukri.org, which has led to the disappearance of the link to this Policy Brief.

Suggestion on how to cite:

MacInnes J, Spijker J (2014), Policy Brief For "Flexible Aging: New Ways To Measure The Diverse Experience Of Population Aging In Scotland”. University of Edinburgh. 


\title{
Policy Brief for "Flexible aging: new ways to measure the diverse experience of population aging in Scotland"
}

\author{
John MacInnes and Jeroen Spijker, University of Edinburgh
}

This ESRC-SDA funded project takes a demographic approach using new metrics to studying population ageing.

\section{Key findings}

- Until now, most notions of dependency are false.

- As an average, the UK population is younger rather than older compared to 1950.

- Old age dependency has declined rather than increased since 1980 as life expectancy at older ages and female labour force participation have increased.

\section{Background}

Population ageing has become a core policy concern because of the supposed implications of current and projected population age structures for future economic performance and the viability of pension, health and social care systems. However the debate has usually been based on definitions of 'old age' that use fixed age categories (e.g. taking the current male retirement age of 65 as a cut-off point) or that underestimate the continuous improvements in mortality and morbidity at older ages. An 'average' 60 year old, for example, enjoys longer life expectancy than their equivalent of only one decade ago. Moreover, not only old-age mortality has declined since mid-way last century, but older people are also, on average, healthier as they have become more active and health conscious. Accordingly, the onset of chronic disease is being delayed, suggesting that biological ageing or senescence is slowing down. Up until now, "population ageing" has often been considered as something "bad", "new" or that "it will overwhelm us all". As we have shown in our research, these claims are false, in part because the indicators of population ageing that are used to make these claims are poor, while the metaphor of 'ageing' is also misconceived. Individuals are born, grow old and die. Populations do none of these things, but what does change is the distribution of ages. Fewer births and longer lives increase the average age of the population as better public health, improved medical knowledge and technology and better education have doubled life expectancy at birth. Moreover, whoever laments population ageing should answer a simple question: who should die sooner?

\section{Method}

Perhaps the best known indicator of the burden of population ageing is the Old Age Dependency Ratio (OADR). However, it counts neither the number of dependent older people nor the number who sustain them. It merely takes a cut-off point (the state pension age) and assigns adults to the two sides of the ratio accordingly. This might be a useful rule of thumb if the relative size of these two age groups tracked the volume of old age dependency, but it does not. We propose an alternative measure that gives a more accurate and very different picture.

Counting dependent older people - Since the main factor behind the ageing population is increasing life expectancy, age is a poor measure of its burden. In 1900 mean remaining life expectancy (RLE) for a 65 year old woman in England and Wales was 11 years. Today she could expect to live another 21 years (10 and 18 years respectively for men). Yet, the OADR defines all people above the statutory 
pension age as dependent, regardless of their economic, social or medical circumstances, overlooking the fact that rising life expectancy makes these older people younger, healthier and fitter than their peers in earlier cohorts. Currently 1+ million are still working, mostly part time, many with valuable experience or specialist knowledge. Many have spending power, do volunteer work vital to the third sector or look after grandchildren. We know that most acute medical care costs occur in the final months of life, with the age at which these months occur having little effect. At least some forms of disability are being postponed to later ages. Good data on population health by age are available only for the last decade, but RLE data are a robust substitute because they provide a more accurate picture.

Counting the working population - The OADR assumes that everyone of working age actually works. However, the knowledge economy keeps young people in education for longer while many older workers choose or are obliged to retire early. Meanwhile, greater sex equality and dual career families have added 5 million women workers to the British labour market over the past 50 years. Using age to define the working population thus makes little sense. Indeed, there are more dependents of working age than there are older people who do not work.

\section{The Real Elderly Dependency Ratio}

Using the population in ages with a RLE of 15 years or less to estimate the volume of dependency and taking the actual numbers employed, irrespective of age, rather than all those of working age, as the denominator we came up with the The Real Elderly Dependency Ratio (REDR):

$$
\mathrm{REDR}=\frac{\# \text { men and women in age groups with } \mathrm{RLE} \leq 15 \text { years }}{\# \text { men and women employed }}
$$

We showed that for England and Wales (see Figure) and other countries both the level and trend of this indicator is very different to the standard OADR (including when the latter is adjusted for recent changes in the pension age). We discovered that the REDR turns out to have fallen substantially in the UK and elsewhere over recent decades, and is likely to only slowly increase in the UK over coming decades:

Figure. Old age dependency ratios, proportion of the population at ages with remaining life expectancy of $\leq 15$ years, and the real elderly dependency ratio, England and Wales 1950-2050
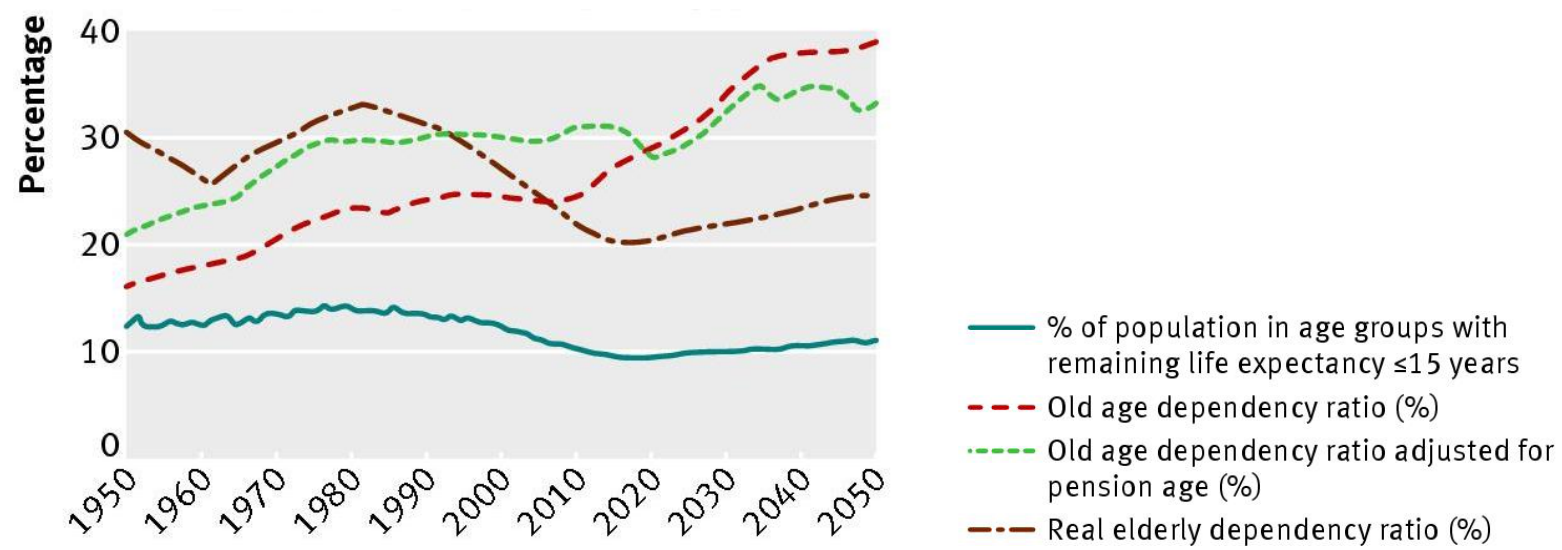

Source: see Spijker and MacInnes. 2013. British Medical Journal;347:f6598. 


\section{Impact of study and policy implications}

Recently, main results of the project have been both presented and published in accessible terminology for academics, policy makers and the general public in academic and journalistic articles (see under further reading). Our main objective has been to show the fundamental nature of population ageing and its inherently contradictory features as we think that better understanding and management of population ageing will make a significant contribution to the effectiveness of public intervention and planning.

The different story of population ageing told by the REDR, particularly the false notion of oldage dependency, has several important implications. The first is that population ageing is no excuse for trimming the welfare state or arguing that pension arrangements are unsustainable. When the state pension age was lowered to 65 in 1928 the UK output per capita was one quarter of today's level. Over the last 130 years average annual working hours have halved. Thus the only barrier to letting the proportion of people's lives spent in retirement rise, or to sustaining or growing the welfare state, is political imagination and courage.

Moreover, the REDR underscores that rising demand for health-care and social services is not a function of having a larger share of people above a specific age. Factors like progress in medical knowledge and technology, and the increasing complexity of age-related comorbid conditions, are far more relevant.

Finally, the conviction that old age created poverty is also no longer the case. The poor who are old now were almost all poor when they were young. The efforts of the welfare state are therefore better directed towards the young. Of particular importance is avoiding high youth unemployment as it is exceedingly difficult to recover from a bad start to a labour market career. What economists refer to as 'scarring' can last a lifetime.

\section{Further Reading}

The following seven articles were written in the framework of this project:

MacInnes J, Spijker J (2014), The politics of population ageing. Policy Network. Published 6 Feb. https://www.pure.ed.ac.uk/ws/portalfiles/portal/16532686/The_politics_of_population_ageing.pdf

MacInnes J, Spijker J (2014), Getting older doesn't make you more conservative. The Conversation. Published 11 Jan https://theconversation.com/getting-older-doesnt-make-you-more-conservative-21729

MacInnes J, Spijker J (2013), Public Policy's Senior Moment. Project Syndicate. Published 27 Dec. http://www.project-syndicate.org/commentary/john-macinnes-and-jeroen-spijker-propose-a-new--moreaccurate-measure-for-population-aging-s-economic-impact

MacInnes J, Spijker J (2013), Hard Evidence: can we afford an ageing population? The Conversation. Published 18 Dec. https://theconversation.com/hard-evidence-can-we-afford-an-ageing-population-21386

MacInnes J, Spijker J (2013), Forget the ageing population, we're actually getting younger. The Conversation. Published 13 Dec. https://theconversation.com/forget-the-ageing-population-were-actually-getting-younger$\underline{21249}$

Spijker J, MacInnes J (2013), Population ageing:the timebomb that isn't? British Medical Journal 347:f6598. http://www.bmj.com/content/347/bmj.f6598

Spijker J, MacInnes J (2013), Population ageing in Scotland: Time for a re-think? Scottish Affairs 85: 53-74.

\section{Contact}

